\section{Online integrity training falls short}

Education in the responsible conduct of research (RCR) will receive a long-overdue critique at a conference discussing the work of the US Office of Research Integrity on 3-5 April in Baltimore, Maryland.

The US National Institutes of Health has required recipients of training grants to receive RCR education since 1990, and it has been a prerequisite of the US National Science Foundation (NSF) since 2010 for all students and postdocs funded by its research grants.

In 2012, under contract from the National Center for Professional and Research Ethics at the University of Illinois, I reviewed the NSF policies of 27 major universities. I found that 26 depend solely (12) or largely (14) on online RCR training, with all but two using the Collaborative Institutional Training Initiative (CITI; www.citiprogram.org).

Outsourcing ethics education in this way suggests that RCR education is developed and executed with an eye to expedience rather than excellence. It risks sending a message to young researchers that the university and its scientists do not place much emphasis on responsible conduct.

European universities, which do not yet have RCR mandates in place (see N. Axelsen and X. Bosch Nature 489, 208; 2012), should learn from the US experience and develop meaningful RCR programmes. These need to be taught by the people the students want to emulate - scientists.

Kenneth D. Pimple Indiana University, Bloomington, USA. pimple@indiana.edu

\section{Too much reliance on anonymous tip-offs}

Several scientific journals and ethics committees are deferring to anonymous judgment when it comes to charges of plagiarism and falsification of results in published research papers. As a bioethicist, I believe that this practice is risky, even when the tipster's views are valid: it could itself damage the integrity of scientific research.

The authors of the blog Retraction Watch (www. retractionwatch.com) hold the view that anomalies detected by someone using the pseudonym 'Clare Francis' are useful to scientific journals, irrespective of his or her anonymity (see A. Marcus and I. Oransky Lab Times $7,39 ; 2011)$. But this unorthodox 'review' process pollutes the ethics that underpin scientific progress.

The practice could stimulate witch-hunting and pillorying. There is a danger that researchintegrity committees could succumb to moralistic drift and confuse errors with misdeeds, underestimating context and a scientist's professional record. Stigmatized researchers might be tempted to exact revenge on their colleagues.

In my opinion, this is not the way to improve the moral standards of science's contribution to society or to build public engagement in science. Gilberto Corbellini Sapienza University of Rome, Italy. gilberto.corbellini@uniroma1.it

\section{Standardize records of place of death}

We suggest that a record of the place of death should be incorporated into deathregistration data as a useful additional health metric (Nature 494, 281; 2013).

End-of-life care is a major public-health issue, given the rising number of deaths from chronic illnesses that have multiple and complex symptoms. Knowing where people die can be an indicator of where they were cared for, which is important for allocating healthcare resources and for assessing related public-health policies.
Despite surveys that show a prevailing preference for home death among patients, caregivers and the public, most deaths in Europe still occur in hospital (B. Gomes et al. BMC Palliat. Care 12, 7; 2013). We are supplying Portugal with such survey information to help improve the recording of place of death in its electronic deathregistration system.

The place of death is registered in a few other countries (the United States and Canada, for example), but its categorization is inconsistent - sometimes even within a country. Location categories need to be internationally standardized (J. Cohen et al. BMC Public Health 7, 283; 2007) and this potentially valuable health-care resource put under the political spotlight.

Barbara Gomes ${ }^{\star}$ King's College London, UK.

barbara.gomes@kcl.ac.uk

${ }^{*}$ On behalf of 4 co-signatories (see go.nature.com/jm4tki for full list).

\section{Nuclear-waste site geology is paramount}

As a former geological adviser to the UK government on nuclearwaste repositories, I would like to clarify some points in your discussion of the quest for a British nuclear-waste disposal site (Nature 494, 5-6; 2013).

Nirex was a UK government agency (not an "independent group") that was set up in 1982 to find a geologically suitable site. In 1991, it chose Sellafield in Cumbria - one of two nuclear industry sites - from a list of 537 potentially available locations. Neither of these two sites was among the geologically most suitable, according to Nirex's seven-stage selection process. Its 1997 planning application for an underground laboratory at Longlands Farm, near Sellafield, failed because the inquiry inspector concluded that Nirex did not understand the site's complex geology (see go.nature.com/5p7yae).

The government's 2008 White Paper, Managing Radioactive Waste Safely (MRWS), put the fact that Cumbria volunteered to consider housing the waste ahead of scientific considerations. This contravenes international guidelines and practice in which national geological searches are conducted before seeking permission from local communities.

To some, this seemed like a back-door attempt to return to the Sellafield district, ignoring both the inspector's original report and the geological problems of the area (see go.nature.com/wob9rf).

You blame a "lack of political will" for the failure of the Nuclear Decommissioning Agency to "sell the facility to local residents". On the contrary, the now-defunct West Cumbria MRWS process spent $£ 3.5$ million (US\$5.3 million) on publicity over the past two years.

So Cumbria County Council has demonstrated strong political will by listening to both the geological and the democratic arguments against proceeding with a deep repository for nuclear waste in the region.

David Smythe University of Glasgow, UK.

dks1e@udcf.gla.ac.uk

\section{CORRECTIONS}

The Outlook article 'A many layered thing' (Nature 492, S52-S54; 2012) contained an error in the graphic 'Caught in a loop'. The labels for the Th1 and Th17 cells were shown switched over.

And in the Outlook article 'Mine, all mine!' (Nature 495, S2-S3; 2013), the map 'Where does gold come from?' originally presented world gold production figures in kilograms but with the label of tonnes.

The values have been corrected online to show tonnes. 